\title{
Manufacturing of macro scale composites with strengthening structure made with use of SLM technology - machinability
}

\author{
Wytwarzanie kompozytów w skali makro \\ ze strukturą umacniającą generowaną w technologii SLM - skrawalność
}

\author{
EMILIA BACHTIAK-RADKA \\ DAMIAN SOBKÓW \\ KRZYSZTOF FILIPOWICZ *
}

\begin{abstract}
Attempts of defining of machinability of manufactured details relative to research aimed to create macro composites with defined strengthening structure made using selective laser melting (SLM technology) were presented. The structures are made of significant different materials than the filling and that causes a problem with choosing the right tools and parameters for the whole element. That is why there were manufactured preliminary tests of achieving similar surface structure while machining manufactured samples. Measurements of surface parameters were made using confocal microscope. Borders between strengthening structure and filler were observed in order to check if the materials were separated during machining. There was also observed wear of machining tools made of different materials after machining with different parameters.
\end{abstract}

KEYWORDS: composites, machinability, SLM

The use of composites, which are a combination of various materials with metals, is becoming more and more common. Metal matrix composites (MMC) for 40 years are used in areas of industry where there is a need for materials with improved mechanical properties and low density. The properties of composites vary depending on the combination of reinforcing structures and filling [1].

The test results available in the literature $[2,3]$ indicate discrepancies between the machinability of MMC materials and alloys used in the matrix, depending on the reinforcement used.

MMC production is based on the dispersion of the fortifying phase in a random manner in the matrix material. A special case is the use of the SLM method for the preparation of nanoparticle composites suspended in a metal matrix [4].

Thanks to the development of incremental manufacturing techniques, more and more complex geometrical structures can be created. During the research on microcracking structures [5], we obtained promising results of SLM

\footnotetext{
* Mgr inż. Emilia Bachtiak-Radka (emilia.bachtiakradka@zut.edu.pl), mgr inż. Damian Sobków (damian.sobkow@zut.edu.pl), dr inż. Krzysztof Filipowicz (kfilipowicz@zut.edu.pl) - Wydział Inżynierii Mechanicznej i Mechatroniki Zachodniopomorskiego Uniwersytetu Technologicznego w Szczecinie
}

manufacturing of components with good durability in the most important directions for the given construction at the lowest mass. The possibility of obtaining structures with strictly defined strength properties under static loads has been discovered, however their low mass causes problems with damping vibrations in such elements. In this connection, the idea to increase the damping properties, for example by filling the space between the truss beams in a similar way, arose. Then a composite structure is created on a macro scale, in which the strengthening phase is a truss of a certain strength created in SLM technology with a fill (matrix) of added material.

\section{Description of tests}

Due to the high availability of material and the research already carried out on structures made using SLM, 1.4404 steel was used to produce the strengthening phase. Two types of materials were selected as fillings for the preliminary tests, the properties of which made it easy to combine with the material of the reinforcement structure.

The first of them is the synthetic resin MeCaTeCMeCaFix 100 , characterized by good adhesion to stainless steels and low density $\left(1.5 \mathrm{~g} / \mathrm{cm}^{3}\right)$. The second filler material is solder for TDB 1020 XFC stainless steels, allowing filling of gaps as low as $0.05 \mathrm{~mm}$. These materials were selected and applied in cooperation with the company Messer Eutectic Castolin from Gliwice.

The samples prepared for cutting are shown in fig. 1 .

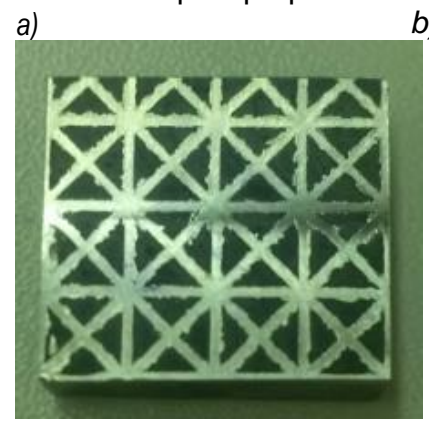
b)

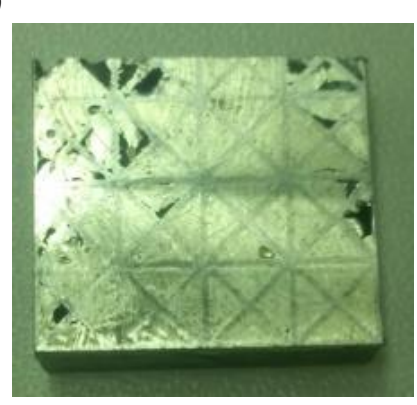

Fig. 1. Photographs of samples prepared for milling: a) sample filled with $\mathrm{MeCaTeCMeCaFix} 100$ resin, b) sample filled with material TDB 1020 XFC 
After initial leveling of the surface and thickness of the samples, the milling of the obtained composites was carried out using two types of cutting inserts. New cutting edges were used each time.

A Sandvik C210.16.R.02 double-edge milling cutter with R390 11 T3 08 plates was used for the tests. The plates were used for machining stainless steels, but with acceptable use for light alloys (4240 carbide grade) and universal inserts (grade 1025) .

The machining tests were carried out on the MIKRON VCE 500 three-axis milling center, which is equipped with the mechanical laboratory of the Faculty of Mechanical Engineering and Mechatronics of the West Pomeranian University of Technology in Szczecin.

For each sample, three transitions were made with a depth of $a_{p}=0.5 \mathrm{~mm}$. In order to observe the influence of the cutting speed on the obtained surface parameters, all samples were machined with the same unit feed rate $f_{z}=$ $0.025 \mathrm{~mm}$. Each time, two cutting speeds were used, recommended for machining stainless steels $\left(v_{c}=290\right.$ $\mathrm{m} / \mathrm{min}$ for 1025 grade tiles and $v_{\mathrm{c}}=240 \mathrm{~m} / \mathrm{min}$ for 4240 grade). Tests were also carried out at speeds close to the speeds recommended for the treatment of non-ferrous materials $\left(v_{\mathrm{c}}=240 \mathrm{~m} / \mathrm{min}\right.$ for grade 1025 and $v_{\mathrm{c}}=270$ $\mathrm{m} / \mathrm{min}$ for species 4240).

\section{Measurement}

All samples were cleaned, after which the geometric structure of the surface was measured with the AltiSurf A520 confocal microscope from Altimet, which was equipped with the Surface Topography (LTP) WIMiM Laboratory.

It turned out that the influence of the cutting speed on SGP parameters is not noticeable, while the difference in the surface structure of samples treated with different plates is clearly visible. Figs. 2-9 show the image of the measuring surfaces of processed samples and their general characteristics.

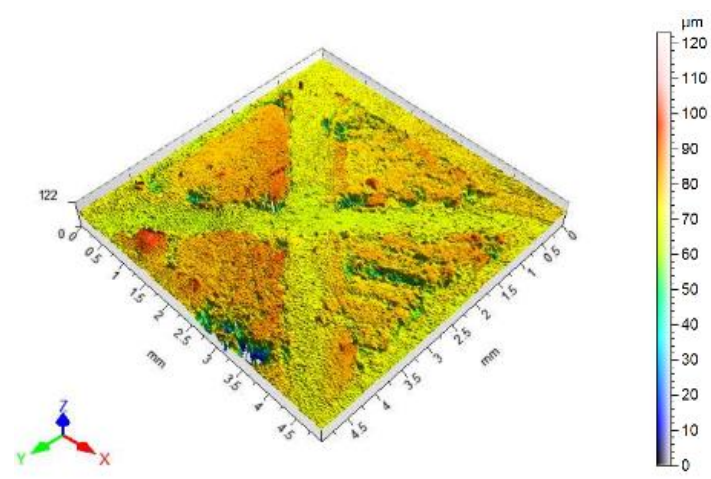

Fig. 2. Image of the surface topography of a sample filled with MeCaTeCMeCaFix 100 resin after treatment with 1025 grade tiles
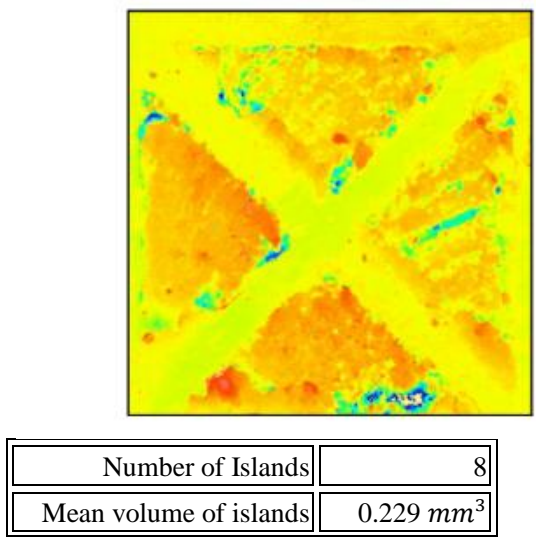

\begin{tabular}{||r|r|}
\hline Mean height of islands & $19.5 \mu \mathrm{m}$ \\
\hline Mean surface of islands & $3.09 \mathrm{~mm}^{3}$ \\
\hline Mean height/surface ratio & $6.32 \mu \mathrm{m} / \mathrm{mm}$ \\
\hline
\end{tabular}

Fig. 3. Analysis of the surface topography of a sample filled with MeCaTeCMeCaFix 100 resin after treatment with 1025 grade tiles

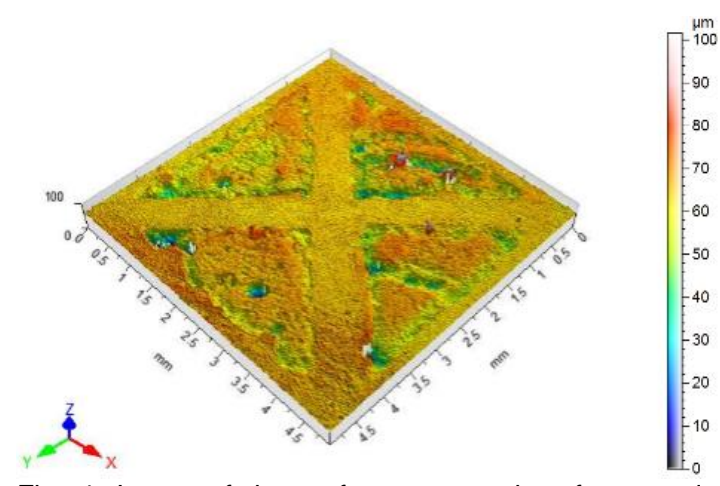

Fig. 4. Image of the surface topography of a sample filled with $\mathrm{MeCaTeCMeCaFix} 100$ resin after treatment with 4240 grade tiles
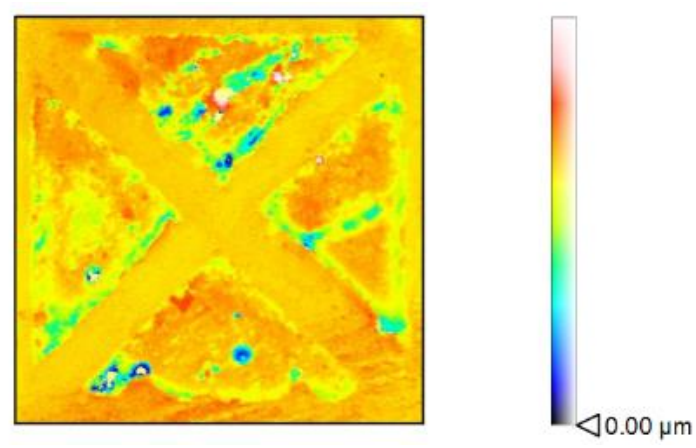

\begin{tabular}{||r|r|}
\hline Number of Islands & 3 \\
\hline \hline Mean volume of islands & $0.524 \mathrm{~mm}^{3}$ \\
\hline \hline Mean height of islands & $101 \mathrm{\mu m}$ \\
\hline \hline Mean surface of islands & $8.23 \mathrm{~mm}^{3}$ \\
\hline \hline Mean height/surface ratio & $12.3 \mu \mathrm{m} / \mathrm{mm}$ \\
\hline
\end{tabular}

Fig. 5. Surface topography analysis of a sample filled with $\mathrm{MeCaTeCMeCaFix} 100$ resin after treatment with 4240 grade tiles

In the case of polymer-filled samples, a better, more uniform surface structure obtained with stainless steel processing boards is clearly visible. Accurate analysis also confirms that in most cases the quality indicators were also better in surface imaging after the confocal microscope measurement.

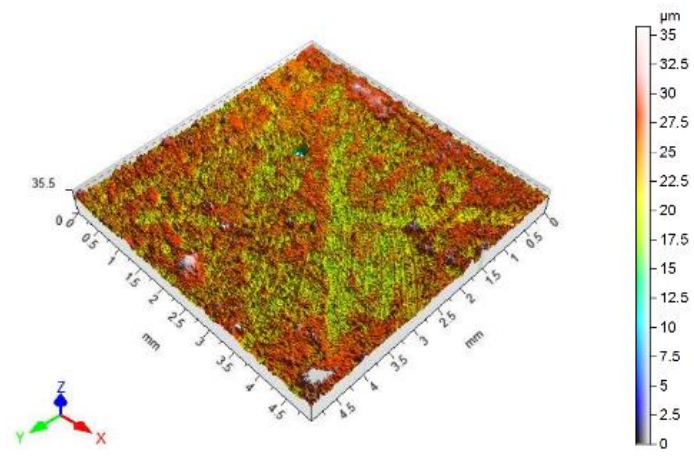

Fig. 6. Image of the surface topography of a sample filled with solder TDB 1020 XFC after treatment with 1025 grade tiles 


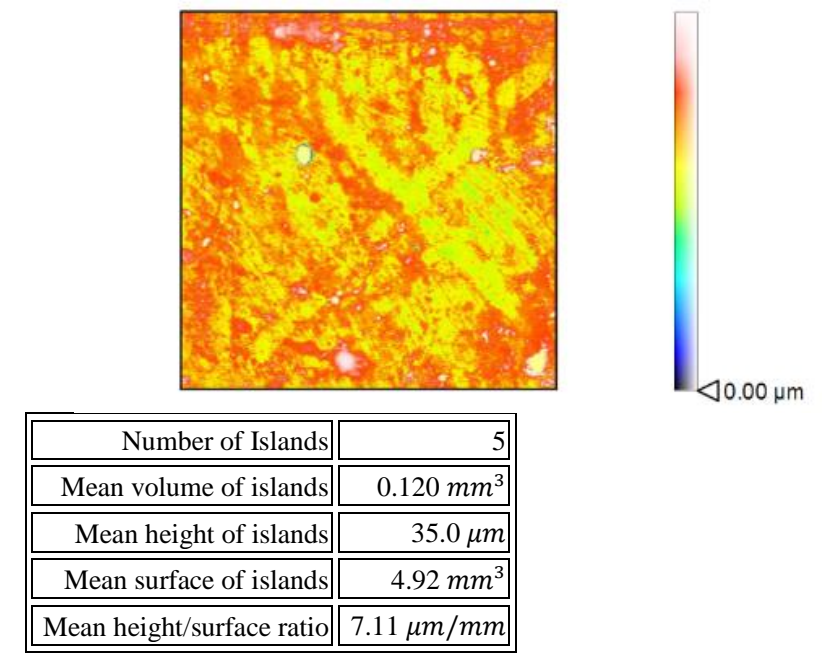

Fig. 7. Analysis of surface topography of a sample filled with solder TDB 1020 XFC after machining with 1025 grade tiles

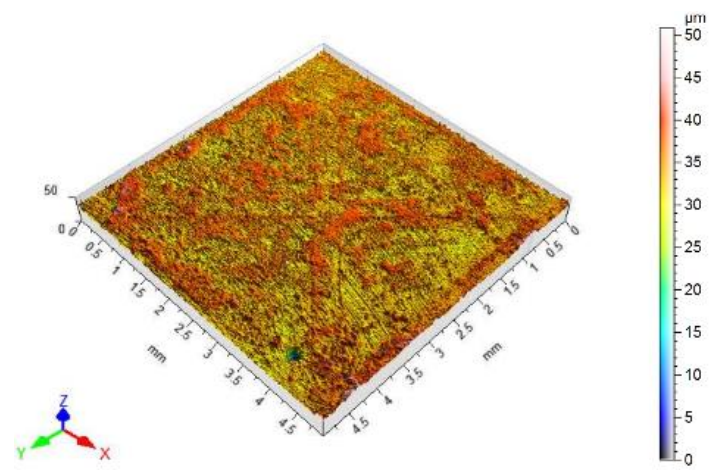

Fig. 8. Image of topography of the sample filled with solder TDB 1020 XFC after processing with 4240 grade tiles
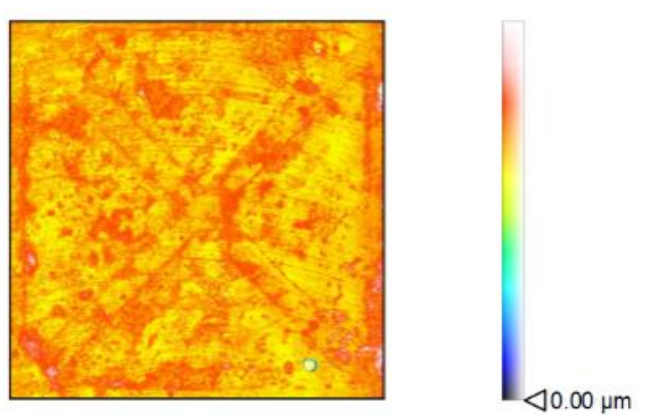

\begin{tabular}{|r|r|}
\hline Number of Islands & 2 \\
\hline Mean volume of islands & $0.430 \mathrm{~mm}^{3}$ \\
\hline \hline Mean height of islands & $49.5 \mathrm{\mu m}$ \\
\hline \hline Mean surface of islands & $12.4 \mathrm{~mm}^{3}$ \\
\hline \hline Mean height/surface ratio & $3.99 \mu \mathrm{m} / \mathrm{mm}$ \\
\hline
\end{tabular}

Fig. 9. Topographic analysis of the surface of a sample filled with solder TDB 1020 XFC after processing with 4240 grade tiles

In the case of samples filled with a metal material, an opposite trend can be seen, i.e. a more uniform surface has been provided by machining using universal tiles. It should be noted, however, that the generally obtained surface structure is much better than the structure obtained on samples filled with polymer, as described by the parameter $\mathrm{Sa}$ (table). This is probably due to a significant difference in the hardness and strength of the combined materials when joining stainless steel and resin.
Both in the samples filled with the metal material and the polymer, the boundary between the surface of the reinforcing material and the filling is noticeable.

\section{TABLE. List of amplitude parameters}

\begin{tabular}{|c|c|c|c|c|c|c|c|}
\hline Sample & $S q$ & $S s k$ & $S k u$ & $S p$ & $S v$ & $S z$ & $S a$ \\
\hline$K 1$ & 8,55 & $-1,84$ & 12,93 & 49,24 & 73,83 & 123,07 & 6,03 \\
\hline$K 2$ & 7,65 & $-2,55$ & 14,97 & 38,17 & 63,43 & 101,60 & 4,71 \\
\hline$S 1$ & 3,07 & 0,01 & 3,38 & 11,47 & 24,29 & 35,76 & 2,47 \\
\hline$S 2$ & 2,86 & 0,22 & 5,84 & 16,21 & 34,58 & 50,79 & 2,30 \\
\hline
\end{tabular}

\section{Conclusions}

Preliminary studies confirm the possibility of producing composites with the reinforcement structure generated using SLM technology. After milling the samples, it turned out that the structures used as reinforcing phase were largely filled with materials used as a matrix-cutting the obtained composites also gives results.

Cutting the obtained composites also gives results. The effect of the filling on the obtained geometric surface structure is clearly visible depending on the tool. A comparison of the measured values of the geometric surface structure indicators is presented in fig. 10 .

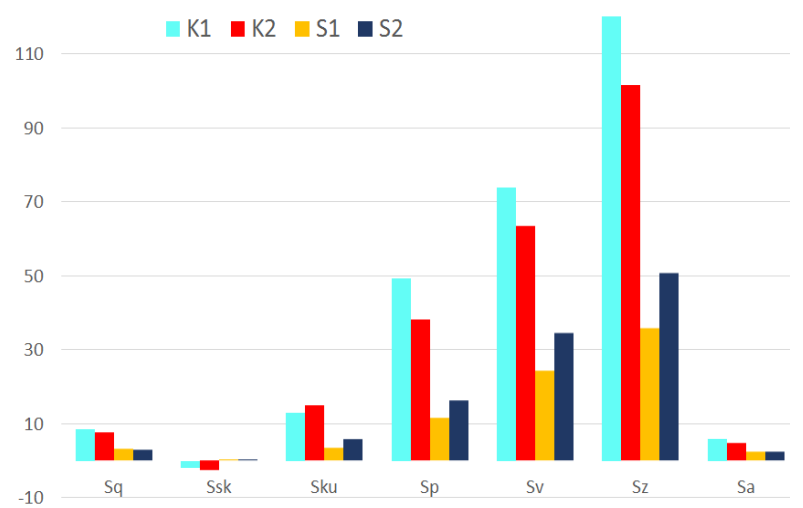

Fig. 10. List of surface quality indicators for samples filled with polymer: K1 - sample treated with 1025 , K2 plates - sample treated with 4240 plates, and samples filled with metal: $S 1$ - sample machined from 1025, S2 - sample machined with tiles from the species 4240

In all the indicators, there is a clear difference between the surface quality of the polymer filled samples and the samples filled with the metal material. In the samples with equal filling, similar values of mean roughness $(\mathrm{Sa})$ and mean square height $(S q)$ were obtained. The asymmetry (Ssk) and kurtosis (Sku) parameters of the surface also retain similar values for samples with the same fill.

In the case of maximum parameters (maximum peak height - $S_{p}$, maximum depth of the cavity - $S_{v}$, maximum height of the roughness $S_{z}$ ), it is possible to indicate clear differences between the values obtained with the use of blades made of different carbide grades. It should be noted that when filled with polymer resin, better parameters were obtained using tiles of a more universal grade (1025), while with metal filling - using the grade recommended for stainless steel (4240).

Further research is carried out to determine the effect of filling materials on the mechanical properties of the elements obtained.

\section{REFERENCES}

1. Pramanik A., Zhang L.C., Arsecularatne J.A. "Deformation mechanisms of MMCs under indentation". Composites Science and Technology. 68 (2008): pp. 1304-1312. 
2. Kanca E., Gunen A. "Investigations on machinability of $\mathrm{Al} 2 \mathrm{O} 3$ reinforced Al6061 Metal Matrix Composites". Journal of Natural and Applied Sciences. 20, 2 (2016): pp. 434-441.

3. Manna A., Bhattacharayya B. "A study on machinability of Al/SiCMMC". Journal of Materials Processing Technology. 140 (2003): pp. $711-716$

4. Biedunkiewicz A. i in. „Właściwości kompozytów MMC zawierających węgliki z układu Ti-Mo-C wytwarzanych metodą nadtapiania SLS/M".InżynieriaMateriałowa. 35, 6 (2014): pp. 451-454.

5. Boruciński M., Królikowski M. "Design of non-uniform truss structures for improved part properties". Advances in Manufacturing Science and Technology. 37, 4 (2013): pp.77-85.

6. www.sandvik.coromant.com/pl-pl (dostęp: 15.06.2018 r.)

Translation of scientific articles, their computer composition and publishing them on the website www.mechanik.media.pl by original articles in Polish is a task financed from the funds of the Ministry of Science and Higher Education designated for dissemination of science. 